\title{
Relações de confiança nas empresas da nova economia infor- macional - uma avaliação dos efeitos da incerteza sobre 0 comportamento organizacional
}

\author{
Marco Tulio Fundão Zanini *
}

\begin{abstract}
Resumo
Este artigo parte de uma perspectiva da economia das organizações para abordar o tema confiança como um mecanismo implítico de controle dentro das empresas. 0 objetivo principal é estabelecer uma relação entre os efeitos das inovações institucionais que caracterizam uma Nova Economia Informacional, e possíveis variações dos níveis de confiança dentro das empresas. Numa perspectiva comparativa, busca-se caracterizar o ambiente das empresas da indústria das tecnologias da informação e comunicação e outras empresas de industrias mais tradicionais da chamada Velha Economia. A hipótese central é que níveis inferiores de confiança poderão ser identificados nestas empresas que atuam mais proximas do paradigma da Nova Economia Informacional. Assim, o artigo sugere um conjunto de proposições para investigação empírica posterior.
\end{abstract}

Palavras-chave: Redes, confiança e Nova Economia Informacional

\begin{abstract}
This article derives from the perspective of the organizational economy to approach the theme of trust as an implicit control mechanism within the companies. The main objective is to establish a relationship between the effects of institutional innovations that characterize a New Informational Economy and the possible variations of the trust levels within the IT and communication industries as well as other companies of more traditional industries of the Old Economy. The core hypothesis is that the lower levels of trust will probably be identified in these enterprises closest to the paradigm of the New Informational Economy. Therefore, the article implies a set of proposals for a later empiric investigation.
\end{abstract}

Key Words: Trust, networks and New Information Economy

\section{Introdução}

Muitas transações econômicas somente ocorrem pela confiança mútua entre pessoas. A cooperação ocasionada pelas relações de confiança entre indivíduos cria uma relação de interdependência, e dessa forma investimentos podem ser recompensados somente se agentes econômicos cumprirem com suas promessas. A confiança é um fenômeno social que recentemente vem sendo abordado em estudos de economia (ARROW, 1974; OUCHI, 1980; KREPS, 1990; OSTROM, 1990; WILLIAMSON, 1993; CHILESe McMACKIN, 1996; RIPPERGER, 1998; GIBBONS, 2000), sociologia (COLEMAN1990; GAMBETTA, 1988; FUKUYAMA, 1996; LUHMANN, 2000) e de gestão organizacional (ZAND, 1972; WHITENER et al, 1998; DIRKS e FERRIN, 2001).

Acadêmicos e pesquisadores vêm comprovando a importância da confiança interpessoal na promoção de relações consensuais e da cooperação entre os indivíduos nas empresas. O papel implícito da confiança interpessoal nas funções de coordenação e controle de muitas tarefas organizacionais tem sido observado, o que contribui, por exemplo, para a transferência do conhecimento (ROLLAND e CHAUVEL 2000, ROBERTS 2000), para a melhoria da eficiência e da produtividade organizacional (RING e VAN DE VEN,1992; BRADACH e BC"Doutorando na Universidade Otto- von- Guericke Magdeburg,Alemanha. Bolsista CAPES no exterior. E- mail: marco.zanini@ student.uni-magdeburg.de. Endereço:
Rua Francisco Otaviano 60 / 206 - Copacabana - Rio de Janeiro - RJ - 22080-040.

Artigo recebido em abril de 2005 e aceito para publicação em julho de 2005. 
CLES 1989; LANE e BACHMANN, 1998) e para a redução dos custos de transação (KREPS, 1990; CHILES e McMACKIN, 1996; BUTTER e MOSCH, 2003). O crescente interesse sobre o tema nos estudos de economia organizacional está relacionado com a busca de soluções para o dilema cooperação versus competição dentro das empresas contemporâneas.

Coriat e Guennif (1998) afirmam que os conceitos econômicos sobre confiança foram desenvolvidos como resposta à incerteza entre os agentes econômicos, devido à variedade de possíveis comportamentos de cada parceiro numa interação. Nesse sentido, Luhmann (2000, p.94) observa que as relações de confiança incondicional geradas normalmente por relações familiares ou sociedades de pequena escala não podem ser automaticamente transferidas para sociedades complexas baseadas na divisão do trabalho. Assim, relações de confiança são necessárias para a reconstrução de instituições sociais, tais como as redes de amizade e as relações hierárquicas baseadas na autoridade.

Abordando a confiança interpessoal do ponto de vista econômico, este estudo tem como foco a relação entre as mudanças nas condições de trabalho, que afetam diretamente o comportamento organizacional, e a possível variação dos níveis de confiança interpessoal dentro das empresas. Alguns estudiosos como Castells (1999), Burton-Jones (1999), Dantas (2002), Cooper e Burke (2002) e Argandona (2003) têm observado os efeitos dessas mudanças nas últimas décadas na configuração de um novo ambiente institucional, segundo o paradigma da nova economia informacional (NEI). Segundo esses estudiosos, essa transformação vem ocorrendo principalmente na indústria de tecnologia da informação e comunicação (TIC), historicamente o setor responsável pela recente revolução tecnológica.

Essas empresas têm algumas características singulares, por influência de um conjunto de inovações institucionais, cujos efeitos podem ser melhor percebidos se as compararmos com as empresas da tradicional "velha economia". Da perspectiva organizacional de comunidades bem estabelecidas através da socialização numa cultura organizacional consistente - constituídas por indivíduos que interagem a longo prazo e têm objetivos comuns à configuração das novas condições de trabalho, nota-se profundas mudanças nas relações interpessoais. Freqüentemente, no âmbito do comportamento organizacional, esse processo resulta em maior competição interna e em relações trabalhistas fundamentadas em contratos transacionais de curto prazo, igualmente desencadeadas por mudanças estruturais na oferta de emprego. A principal conseqüência é uma menor interdependência entre empregado e empregador, além de uma maior insegurança e instabilidade, especialmente, pela falta de mecanismos institucionais de proteção ao empregado.

Mesmo considerando que essas inovações institucionais tenham igualmente influenciado o ambiente de trabalho em outros setores da economia, Argandona (2003) afirma que seus efeitos podem ser melhor observados nas empresas mais próximas do paradigma da nova economia informacional, como no setor de telecomunicações e de informática.

A principal hipótese deste estudo é que, geralmente, menores índices de confiança interpessoal poderão ser observados nesse setor em comparação com as empresas da chamada velha economia. Outro pressuposto aqui levantado é o de que os níveis de confiança interpessoal podem estar relacionados a outros aspectos referentes à gestão, tais como o nível de comprometimento dos empregados, as taxas de rotatividade de mão-de-obra (turnover) e a performance.

\section{A confiança como um bem econômico}

De uma perspectiva econômica, a confiança é freqüentemente compreendida por uma abordagem mais racionalista. Gibbons (2000) afirma que, não se abstendo de outros motivos das interações sociais, o foco em "puros motivos econômicos" entende confiança de uma forma mais "calculista", não rejeitando sua mais ampla definição social ou relacional, não menos importante para a análise econômica. Confiança é considerado um notável e eficiente "lubrificante" para as trocas econômicas, e o mais eficiente mecanismo para conduzir as transações econômicas (ARROW, 1974). Ao tratar dos sistemas econômicos, Arrow (1974, p.23) afirma que a confiança 
gerada entre os indivíduos é uma forma de contrato implícito ou uma commodity que não pode ser facilmente adquirida ou comprada.

Nas hierarquias, a confiança é considerada um mecanismo implícito de coordenação e controle, resultado de relações interpessoais e normas sociais, que contribui para a formação de ações cooperativas entre os membros de uma organização (BRADACH e ECCLES, 1989, p.282). Além dos mercados e da hierarquia, tradicionais formas de coordenação das transações econômicas controladas respectivamente por preço e autoridade, um grupo de estudiosos tem proposto o estudo das redes como uma forma complementar de coordenação das transações econômicas (BRADACH e ECCLES, 1989; NOOTEBOOM, 1996; OUCHI, 1980; RING e VAN DE VEN,1992).

Em contraste com as tradicionais formas de coordenação, as redes de relacionamentos coordenam as transações econômicas através de meios menos formais, mais igualitários e cooperativos (THOMPSON, 1998, p.171). Bradach e Eccles (1989) afirmam que longe de serem perfeitas substitutas, as redes de relacionamentos funcionam como uma forma de coordenação complementar para mercados e hierarquias, tendo como principal mecanismo de controle, a confiança entre os agentes interativos. Ouchi (1980, p.248) ressalta que mercados, hierarquias e clãs (ou redes de relacionamento) são três mecanismos distintos que podem coexistir empiricamente em diferentes níveis, em qualquer organização.

As redes funcionam através de relações interpessoais baseadas na reciprocidade, nas crenças e em valores comuns que coexistem com a autoridade formal legitimada. Diversos estudos empíricos (LORENZ, 2000; PUTNAM, 1996; CASTELLS, 1999) têm constatado a existência de formas de coordenação em redes formadas por grupos de empresas ou grupos sociais informais que vão além dos limites tradicionais da empresa (redes interorganizacionais) ou, mesmo, grupos sociais informais dentro da mesma organização (redes intraorganizacionais). Essas redes de relacionamento baseadas na confiança podem assumir diversas formas em diversos níveis, envolvendo indivíduos, grupos e empresas. A tabela 1 apresenta os diferentes tipos de controle e coordenação das atividades econômicas.

Tabela 1 - Diferenças entre mecanismos de coordenação

\begin{tabular}{cccc}
\hline & \multicolumn{3}{c}{ FORMAS DE COORDENAÇÃO } \\
\hline Critério de diferenciação & Mercado & Hierarquias & Redes \\
\hline $\begin{array}{c}\text { Controle pelo comando do } \\
\text { comportamento }\end{array}$ & Preço & Autoridade & $\begin{array}{c}\text { Confiança } \\
\text { (normas e valores) }\end{array}$ \\
\hline $\begin{array}{c}\text { Controle pelo monitoramento do } \\
\text { comportamento }\end{array}$ & $\begin{array}{c}\text { Controle por } \\
\text { output }\end{array}$ & $\begin{array}{c}\text { Controle } \\
\text { comportamental }\end{array}$ & Autocontrole \\
\hline
\end{tabular}

Fonte: Vogt (1997, p.57, tradução do autor).

A teoria das redes encontra bons argumentos na abordagem econômica, através dos estudos de Hayek (1998) sobre a coexistência das formas de governança espontânea e intencional, ou através dos experimentos de Axelrod (1984) com jogos cooperativos. Hayek (1998) argumenta que duas diferentes funções de governo não podem ser claramente separadas como "espontâneas" e "intencionais". Quanto à forma espontânea, Hayek argumenta que ela não pode ser adquirida simplesmente pelo comando - como no caso do governo intencional mas pela melhoria das regras de interação e comportamento que podem favorecer a sua formação. Axelrod (1984) demonstra através de estratégias cooperativas, dois pontos importantes que podem ilustrar a formação das redes. Primeiro, as expectativas mútuas de encontros repetidos num período indeterminado de tempo são suficientes para induzir agentes interativos a agirem de forma cooperativa, e dessa forma a confiança pode se desenvolver de modo apropriado. Segundo, a cooperação entre os agentes pode ser alcançada sem necessidade de uma autoridade central. 
Sen (1967) demonstra que a cooperação pode emergir de um consenso razoável, em situações percebidas como mutuamente benéficas, quando o bem coletivo é tecnologicamente limitado e os recursos são escassos, como é o caso dos recursos orçamentários de uma empresa.

Freqüientemente, a teoria da decisão racional estabelece certa similaridade entre cooperação e confiança interpessoal. A confiança é comumente mostrada na teoria dos jogos (AXELROD, 1984; KREPS, 1990; GIBBONS, 2000) como um elemento que promove a cooperação entre parceiros interativos. Assim, para que haja relações de cooperação baseadas na confiança é necessário que ocorram consecutivas interações entre indivíduos durante um razoável período de tempo. Dessa perspectiva, considera-se provável a continuidade dessas interações, de forma que o seu término seja randômico ou imprevisível. Além do mais, os agentes interativos devem perceber que os benefícios e as vantagens decorrentes dessas interações de longo prazo prevalecem em detrimento de possíveis tentações de ganhos individuais no curto prazo. Por outro lado, a confiança pode se manifestar ainda quando agentes interagem intensamente em outros contextos, com a presença de um terceiro ator, buscando preservar sua reputação.

No entanto, a pura perspectiva racionalista não explica como a confiança contribui para o estabelecimento de formas de cooperação. Para Fukuyama (1996), é porque a confiança não é uma precondição para a cooperação, e pode ser alcançada sem estar necessariamente calcada em relações de consenso ou de confiança. Isso tem sido provado recorrendo-se a formas de produção bem-sucedidas, baseadas na coerção, segundo o modelo taylorista. A coerção tem sido (e ainda é) amplamente aplicada como meio para garantir formas cooperativas entre os indivíduos, mas não é necessariamente uma alternativa para as relações baseadas na confiança.

Enquanto a aplicação de meios coercitivos dispensa maior preocupação pela promoção da cooperação para tarefas específicas, esta possivelmente promove situações de maior insatisfação e a percepção de injustiça e desigualdade, aumentado as chances de um comportamento oportunista. Dunn (2000) e Luhmann (2000) compartilham a mesma visão de que a exploração do interesse alheio raramente funciona como um substituto adequado para as relações baseadas na confiança. Por outro lado, como afirma Gambetta (1988), se existe confiança em relações de cooperação, igualmente haverá um certo grau de coerção, ou pelo menos ameaça de que ocorra. Diante de relações baseadas na confiança, menos coerção é necessária e vice-versa.

\section{Uma definição funcional de confiança}

Ripperger (1998) propõe uma abordagem econômica para o elemento "confiança", acrescentando uma perspectiva psicológica à tradicional teoria da decisão racional. Sua proposta define de forma mais abrangente o estudo do elemento confiança, esclarecendo sua relação com a cooperação. Para caracterizar uma ação cooperativa baseada na confiança, Ripperger (1998, p.45) considera que haja uma expectativa de confiança e uma ação baseada na confiança (tabela 2):

- expectativa de confiança - é a expectativa de quem confia em outra pessoa, acreditando que ela estará motivada a não agir de forma oportunista;

- ação baseada em confiança - é um investimento voluntário da pessoa que confia, através de uma ação concreta, numa situação de risco comportamental, sem recorrer a nenhum mecanismo explícito de segurança ou controle para se precaver contra um possível comportamento oportunista.

Tabela 2 - Relação entre confiança e cooperação

\begin{tabular}{ccc}
\hline & \multicolumn{2}{c}{ AÇÃO BASEADA NA CONFIANÇA } \\
\hline Expectativa de confiança & Sim & Não \\
\hline Sim & $\begin{array}{c}\text { Cooperação baseada na } \\
\text { confiança }\end{array}$ & $\begin{array}{c}\text { Confiança sem } \\
\text { cooperação }\end{array}$ \\
\hline Não & $\begin{array}{c}\text { Cooperação sem } \\
\text { confiança }\end{array}$ & $\begin{array}{c}\text { Ausência de confiança e } \\
\text { de cooperação }\end{array}$ \\
\hline
\end{tabular}

Fonte: Ripperger (1998, p.93, tradução do autor.). 
Ainda conforme essa análise, a confiança pode ser entendida como uma predisposição ou expectativa que leve a uma ação calculada envolvendo risco comportamental. Tal expectativa se manifesta através de um estado subjetivo inicial, ou uma reação emocional, traduzido(a) por uma condição cognitiva racional. Dessa forma, um indivíduo consegue avaliar e calcular sua predisposição a se engajar numa determinada situação que envolva risco relativo ao comportamento de outro. Ripperger (1998, p.45) define a confiança como aceitação voluntária e antecipada de um investimento de risco, pela abdicação de mecanismos contratuais explícitos de segurança e de controle contra comportamentos oportunistas, na expectativa de que a outra parte não agirá dessa forma. Nessa mesma linha, Zucker (1986, p.54) define confiança como um conjunto de expectativas compartilhadas por parceiros de interação. Também Luhmann (2000, p.103.) entende confiança como uma expectativa, predisposição ou atitude baseada em experiências pessoais anteriores, que precede a tomada de decisões envolvendo risco comportamental.

É perceptível que na abordagem econômica, a confiança é uma subclasse das situações de risco, no que se refere ao comportamento daquele em quem se confia. Como define Coleman (1990, p.91), "há situações nas quais o risco que se corre depende da performance do outro ator". De acordo Ripperger (1998, p.36), a aceitação intencional e voluntária do risco em condições de vulnerabilidade é central nessa definição. A confiança pode ser vista como uma fonte de motivação intrínseca para que indivíduos se engajem voluntariamente, assumindo determinado risco. Como afirmam Bradach e Eccles (1989): "confiança é um tipo de expectativa que alivia o receio de que o parceiro haja de modo oportunista. Evidentemente, é preciso haver o risco de uma conduta oportunista para que a confiança funcione“. Deutsch (1958 e 1962) enfatiza que só é possível haver confiança nas situações em que as possibilidades de perda ou prejuízo sejam maiores do que as possíveis vantagens advindas da ação. Luhman (2000, p.99) esclarece que, de outra forma, essas situações seriam baseadas apenas num simples cálculo racional, e um indivíduo escolheria a sua ação de qualquer forma porque os riscos permaneceriam dentro de limites aceitáveis. Assim, confiança torna-se necessária apenas se um resultado negativo - pela falta de reciprocidade à confiança depositada - fizer com que um indivíduo possa se arrepender da ação tomada. A confiança mútua que é gerada torna-se uma forma de capital social, de modo que este reduz os custos relativos ao monitoramento e à aplicação de punições e sanções.

Por sua vez, Gillespie (2003, p.04) comenta ainda a existência de um amplo consenso entre pesquisadores e teóricos em confiança quanto à importância central dos conceitos de "risco" e "interdependência"; o que pode ser ilustrado da seguinte forma:

\section{Figura 1}

\section{Ações cooperativas baseadas na confiança}

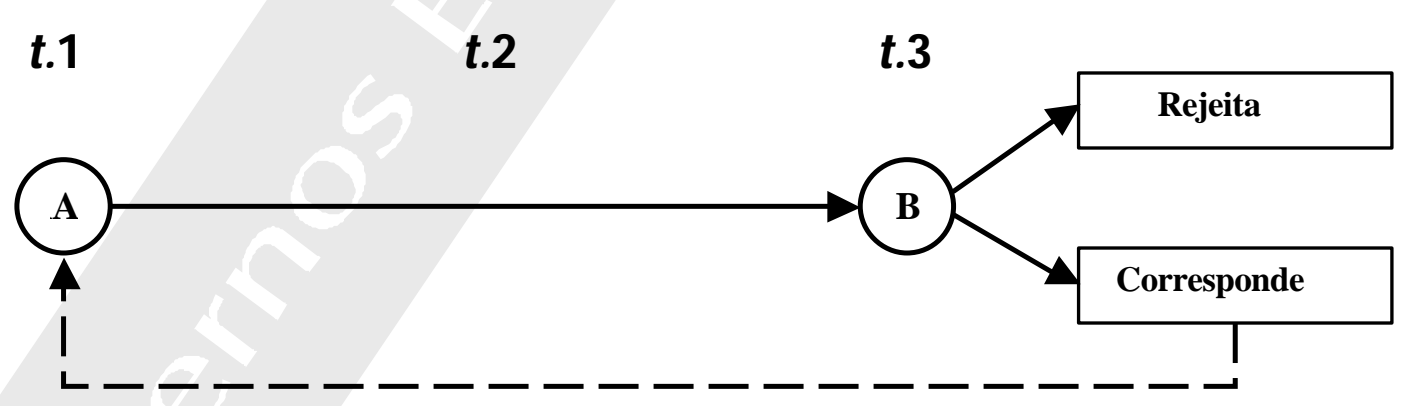

Fonte: Autoria do Autor do Artigo 
De acordo com a figura 1, antes de tudo, $A$ tem uma expectativa de confiança em $B$ (t.1) baseada em reações subjetivas (emocionais) e traduzidas em decisões cognitivas (racionais). Em seguida (t.2), A manifesta essa confiança em $B$ através de uma ação concreta, aceitando voluntariamente o risco em relação ao comportamento de $B$. Nesse momento (t.2), $A$ torna-se vulnerável a uma reação de $B$. Em seguida (t.3), cabe a $B$ rejeitar tal investimento de $A$, não honrando essa confiança, ou corresponder a ela. Caso a confiança de $A$ seja correspondida por $B$, essa reciprocidade dará suporte a uma tarefa que exija cooperação entre ambos os agentes. Somente através dessa cooperação, $A$ e $B$ podem alcançar melhores resultados. Portanto, fica caracterizada uma relação de interdependência entre $A$ e $B$, uma vez que os interesses de um agente não podem ser atendidos sem que haja confiança no outro.

\section{A importância da confiança na perspectiva organizacional}

Quando se considera que as estruturas internas das empresas são hierárquicas e burocráticas, a confiança se torna um mecanismo implícito de controle e coordenação de tarefas comuns entre indivíduos. Da perspectiva da teoria econômica contratual, é possível entender a confiança como um mecanismo implícito de (auto)controle, que uma vez presente nas estruturas organizacionais, permite alta flexibilidade e descentralização, pela redução do controle formal hierárquico e por maiores possibilidades de resultados em burocracias. Max Weber (2002) já havia falado das muitas vantagens da regularidade abstrata das burocracias no exercício da autoridade, como eficientes estruturas para coordenar e sustentar sistemas coletivos de produção pela expansão da racionalidade em detrimento de relações personalistas, dependentes exclusivamente da influência de alguns indivíduos. Nesse sentido, a existência de confiança nas relações burocráticas da organização expande o seu potencial de fomentar relações cooperativas e atingir a eficiência gerencial, através da expansão do campo de controle gerencial por um mecanismo informal.

A perspectiva econômica contratualista busca identificar mecanismos que possam criar incentivos para os participantes de uma interação, de forma que o seu comportamento coletivo atinja o mais eficiente plano de produção. Wolff (1996, p.104-105) afirma que a confiança gerada através da gestão da cultura corporativa (parte implícita do contrato corporativo) deve assegurar a continuidade da cooperação entre as partes (membros da organização), para que se possa atingir, de forma eficiente, melhores resultados. Por trás da visão contratualista, não se pode deixar de observar alguns elementos que são precondição para que haja confiança e que estabelecem uma certa ordem social, como a percepção comum de justiça, reciprocidade e perspectivas de vantagens e benefícios mútuos. A confiança que pode ser gerada dentro do sistema é uma fonte de benefícios extrínsecos - como a informação sobre o comportamento de parceiros - ou intrínsecos, como a motivação para a realização das tarefas organizacionais. Dessa perspectiva, a confiança resulta de um sistema de interações por normas e regras (formais e informais), assim como a gestão da cultura corporativa é um instrumento gerencial determinante para se criar um ambiente favorável a trocas baseadas na confiança. Esse mecanismo se torna ainda mais importante pela crescente demanda por trabalho de maior especialização, baseado no conhecimento, como ocorre em grande parte das empresas da nova economia informacional.

Nesse sentido, os sistemas de produção baseados no conhecimento têm mudado a natureza da transferência da propriedade e, conseqüentemente, a natureza dos custos de transação nas atividades produtivas. Alchian (1967) afirma que uma mudança nesses sistemas implica uma mudança nas consequiências do comportamento dos indivíduos. Conforme Roberts e van den Steen (2001), a crescente importância do conhecimento e do capital humano sugere que os que dispõem desse capital tenham maior participação nos processos de governança corporativa, pelo fato de terem maior participação no capital total das empresas. Essas mudanças vêm criando demanda por novas formas de controle nas atividades econômicas, que sejam mais consensuais, interdependentes e cooperativas, baseadas no interesse mútuo.

Lane e Bachmann (1998) afirmam que os sistemas produtivos baseados em informação e conhecimento intensivo requerem um maior compartilhamento de informação sensível na forma de conhecimento tácito construído pelo consenso. Assim, as relações baseadas na confiança se tornam uma propriedade altamente desejável, não somente como um mecanismo implícito de coordenação das atividades produtivas, mas também como uma 
precondição para se atingir uma performance superior e um diferencial competitivo no novo ambiente de negócios (LANE e BACHMANN, 1998; RING e VAN DE VEN, 1992).

O novo processo de inovação na era informacional surge exatamente com a acumulação seqüencial da experiência de trabalho compartilhado, principalmente, através de grupos de especialistas. Cowan, Jonard e Zimmermann (2004) afirmam que cooperação implica conhecimento mútuo, compartilhamento de rotinas, representações e formas de pensamento. Entretanto, a confiança é necessária porque cooperação envolve incerteza quanto às habilidades do indivíduo e seu grau de confiabilidade. Coriat e Guennif (1998) argumentam que a confiança se desenvolve entre parceiros como resultado de repetidas interações, e que estas fornecem informação adicional e significado sobre o comportamento dos parceiros, reduzindo a incerteza e estabelecendo um mínimo de previsibilidade quanto ao seu comportamento. A proximidade entre os parceiros será construída pela cooperação, e, assim, confiança e aprendizado organizacional estarão intimamente relacionados (COWAN, JONARD e ZIMMERMANN, 2004). Portanto, estabelecer a cooperação e a motivação torna-se um problema fundamental a ser solucionado para que se estimule um processo contínuo e dinâmico de inovação.

Selznick (1957) comenta que o comportamento intencional desses indivíduos que se comprometem mutuamente para fins comuns define o processo pelo qual uma organização desenvolve sua diferenciada competência intelectual no mercado. No entanto, Hayek (1998, p.296) comenta que a grande dificuldade para o gestor é exatamente fazer com que o indivíduo coopere através do recurso ao conhecimento que ele próprio não tem. Dessa forma, a gestão da cultura corporativa - vista acima de tudo como um conjunto de elementos gerenciais físicos e ideológicos - substitui os sistemas tradicionais de monitoramento e controle, mais coercitivos, por meios implícitos e mais consensuais. Essa nova demanda por relações calcadas no consenso pode ser observada na transição dos sistemas de produção de massa, que demandam esforço físico e menor especialização, para os sistemas de produção baseados no conhecimento e que requerem maior concordância de idéias e reciprocidade (figura 2).

\section{Figura 2}

\section{A natureza das relações de trabalho conforme os sistemas de produção}

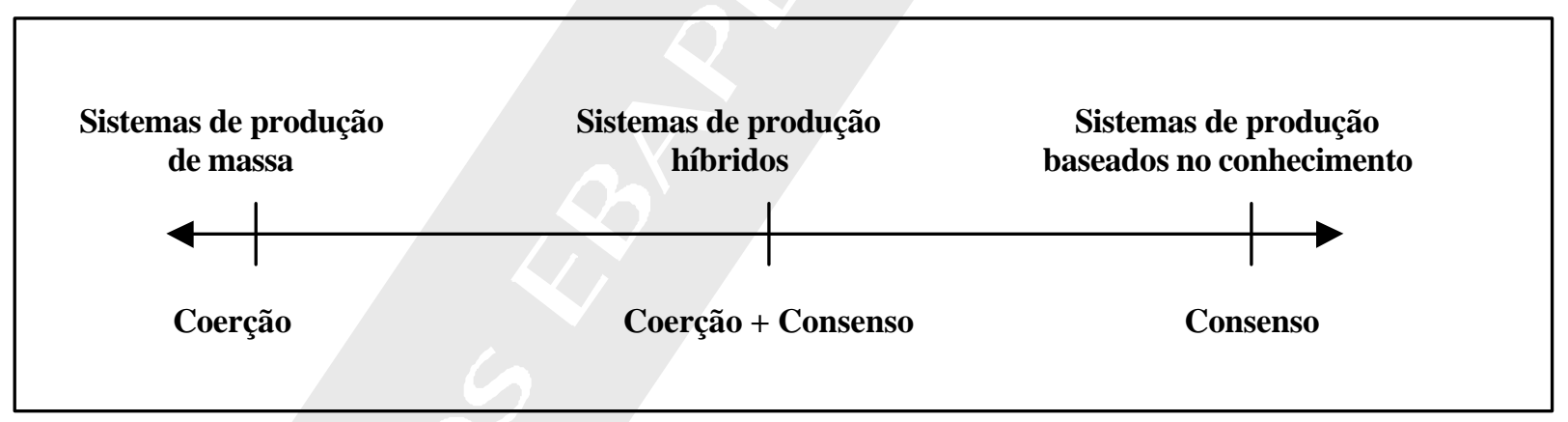

Fonte: Carmen Migueles. Mimeografado. Notas de aulas.(não publicado)

Onde as relações baseadas na confiança existem em determinado nível, é menor a necessidade de mecanismos de monitoração e controle explícitos (com os custos a estes associados). A gestão da cultura corporativa orientada para o fomento de relações baseadas na confiança funciona como um mecanismo implícito de autocontrole para gerar cooperação e comprometimento entre agentes. A confiança conseguida funciona como uma importante fonte de informação e um incentivo para os indivíduos interagirem, constantemente, definindo rotinas e estruturas de cooperação. Dessa forma, a confiança se torna um instrumento estratégico para a promoção da produtividade e da performance.

A confiança é ainda fundamental para o alinhamento de objetivos individuais e organizacionais. Ouchi (1980) argumenta que as burocracias podem apresentar falhas quando se diminui a capacidade de mensuração de per- 
formance, ou quando esta se torna relativamente ambígua. O autor esclarece que organizações burocráticas operam fundamentalmente através de monitoração, avaliação e comando. Nesses sistemas, gerentes se orientam por padrões pelos quais comparam comportamentos ou resultados, exercendo o controle. Esses padrões indicam somente o valor aproximado dos resultados e são objetos de interpretações idiossincráticas. Indivíduos somente percebem esses padrões como "justos" se têm um nível razoável de informação sobre performance. Entretanto, Ouchi (1980) afirma que quando as tarefas organizacionais se tornam únicas e específicas, completamente integradas ou ambíguas por diversas razões, mecanismos burocráticos podem falhar porque se torna impossível avaliar externamente o valor acrescentado por qualquer indivíduo. Nesse sentido, enfatiza Ouchi (1980), qualquer padrão de mensuração de performance que seja empregado será por definição arbitrário e percebido como injusto.

Nessas situações de performance ambígua, a única forma de mediação é a coordenação de tarefas através de redes de relacionamentos que buscam o consenso através da congruência de objetivos. Uma cultura organizacional que sustente relacionamentos baseados em confiança torna-se um instrumento da gestão organizacional ainda mais crítico e desejável, pois como afirma Ouchi (1980), organizações baseadas numa variedade de mecanismos sociais mostram-se eficientes para a redução de diferenças entre objetivos individuais e organizacionais, gerando um forte sentido comunitário.

Beckert, Metzner e Roehl (1998) apresentam um modelo (figura 3) que ilustra a necessidade de confiança no processo de reorganização das estruturas funcionais, quando estas adquirirem formas mais descentralizadas e flexíveis. Nesse processo, a confiança existente nas relações interpessoais se torna um capital social ainda mais importante. A necessidade de confiança no decorrer do processo de reorganização tende a ser crescente, uma vez que o processo de reorganização naturalmente leva a uma maior incerteza, influenciando as rotinas tradicionais de ambientes mais estáveis.

A existência de determinados níveis de confiança assume um valor crescente, uma vez que estes asseguram, implicitamente, expectativas de benefícios mútuos, mesmo na ausência de contratos formais. Recentes estudos empíricos têm endossado esse modelo. Análises sobre a formação de equipes de trabalho virtuais (COUTU, 1998; JARVENPAA, KNOLL e LEIDNER, 1998) demonstraram que pela falta de interação física - com suas propriedades verbais e não-verbais - e de sinergia que acompanha a comunicação face a face, essas equipes apresentam muitos problemas por causa da substituição dos sistemas tradicionais de controle social baseados na autoridade, pelo sistema de autocontrole e autodireção. Não é de causar espanto o fato das equipes virtuais de baixa confiança também apresentarem baixa performance.

\section{Figura 3}

\section{Confiança no processo de reorganização}

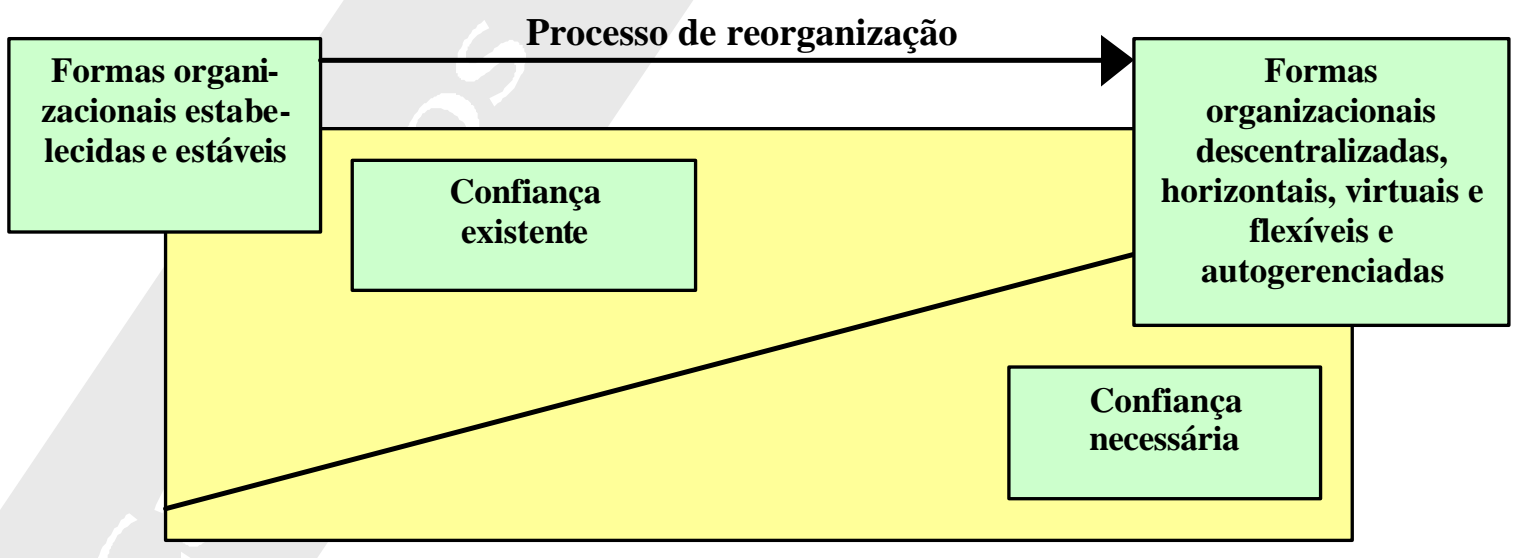

Fonte: Beckert, Metzner e Roehl (1998, tradução do autor). 
A existência de confiança torna-se crítica ainda para as empresas com expectativa de crescimento de demanda. É o que tem sido verificado com frequiência, nos últimos anos, no mercado de produtos e serviços de tecnologia da informação e de comunicação, como telefones celulares, softwares ou produtos/serviços de acesso à internet. Segundo Klein, Crawford e Alchian (1978, p.318), quanto maior a expectativa de aumento da demanda, mais a empresa será dependente de contratos implícitos. A confiança torna-se uma vantagem para as empresas que experimentam um rápido crescimento de demanda, em comparação com as empresas com demandas estáveis ou em declínio.

Dirks e Ferrin (2001) fizeram um levantamento de 43 estudos empíricos sobre a influência da confiança no comportamento dos indivíduos nas organizações, visando entender os benefícios que ela traz. Dentre os muitos benefícios, relacionam a confiança com uma maior satisfação e comprometimento dos empregados, com a melhoria da comunicação, com a aceitação e a delegação de autoridade, com o exercício da liderança, com uma menor competição interna durante as negociações e com a menor incidência de conflitos. Por fim, mas não menos importante, os autores a relacionam com a melhoria da performance tanto individual quanto das equipes de trabalho.

Conforme a análise de Dirks e Ferrin (2001) sobre esses 43 estudos empíricos, espera-se que altos níveis de confiança levem a atitudes mais positivas, a uma maior cooperação, a uma melhor performance e a outras formas positivas de comportamento na organização. No entanto, Langfred (2004) conclui que da mesma maneira que a confiança aumenta a produtividade, situações em que haja excessiva confiança - caso das equipes de trabalho autogerenciadas com grande autonomia -, pode ser prejudicial porque os membros do grupo tornam-se relutantes em monitorar uns aos outros (figura 4.). O resultados encontrados por Langfred (2004) são importantes para se observar uma relação entre mecanismos de controle (explícitos e implícitos) e eficiência gerencial. Através desse estudo pode-se compreender uma relação negativa entre níveis de monitoração explícitos e implícitos, tal como níveis de monitoração vertical (entre superior e subordinado) ou horizontal (entre indivíduos do mesmo nível hierárquico) e os níveis de confiança nessas relações.

\section{Figura 4}

\section{Relação entre níveis de confiança e monitoração em equipes de trabalho autogerenciadas}

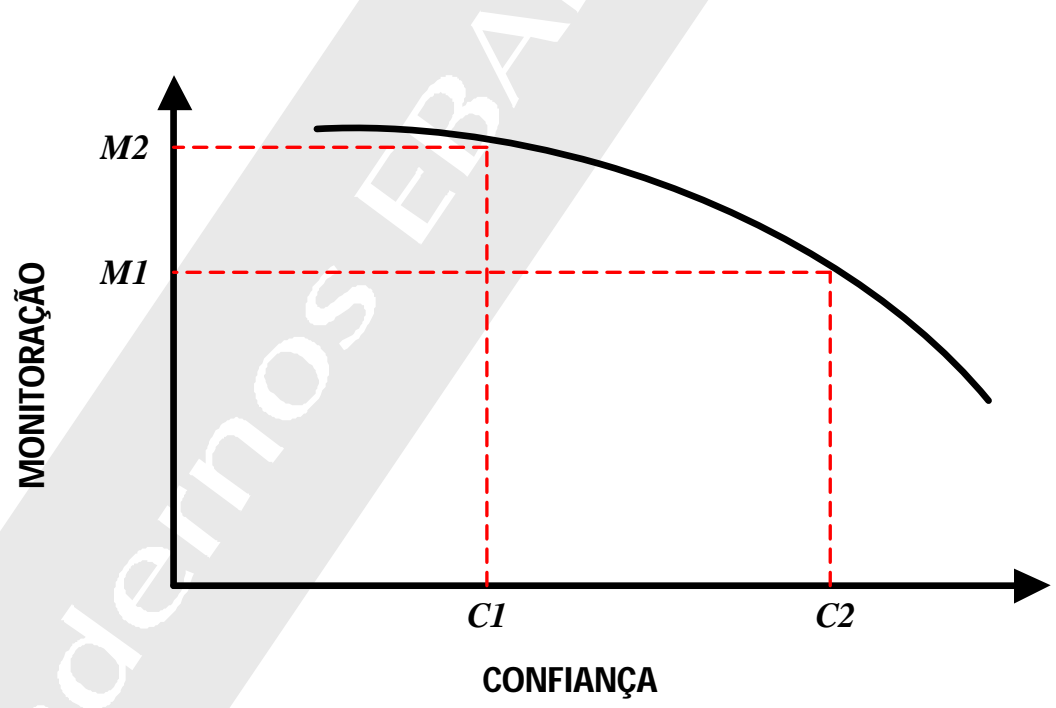

Fonte: baseado em Langfred (2004, p.392, tradução do autor). 
É importante levar em conta os custos associados à escolha de mecanismos tradicionais de monitoração ou de criação de um ambiente de trabalho baseado na confiança. Os mecanismos de controle explícitos baseados em meios coercitivos provavelmente aumentarão as chances de comportamento oportunista. Essas situações envolvem não somente investimento em monitoramento e controle formal, mas possivelmente, uma considerável desmotivação dos indivíduos a se comprometerem voluntariamente com as tarefas organizacionais. Por outro lado, os mecanismos de controle implícitos baseados em relações consensuais vão exigir investimentos contínuos na construção de uma cultura corporativa efetiva. Empiricamente, sempre coexistirão diferentes níveis desses mecanismos de controle empregados nos diversos ambientes organizacionais, de uma forma complementar (figura 5).

Gambetta (1988) argumenta que a promoção da confiança implica custos, que são ainda maiores na falta desta, mesmo que a necessidade de confiança esteja diretamente relacionada à nossa incapacidade de monitorar as ações dos outros. O investimento na confiança ocorre ainda antes de se conhecer o comportamento do outro, em quem se investe. Isso permite supor que esse mecanismo implícito seja mais eficiente do que os mecanismos explícitos de monitoração, principalmente, no que diz respeito aos processos de trabalho criativos baseados em habilidades e na valorização das competências pessoais como estímulo à inovação, através da aplicação do conhecimento.

Figura 5.

Relação complementar entre mecanismos de controle explícitos e implícitos

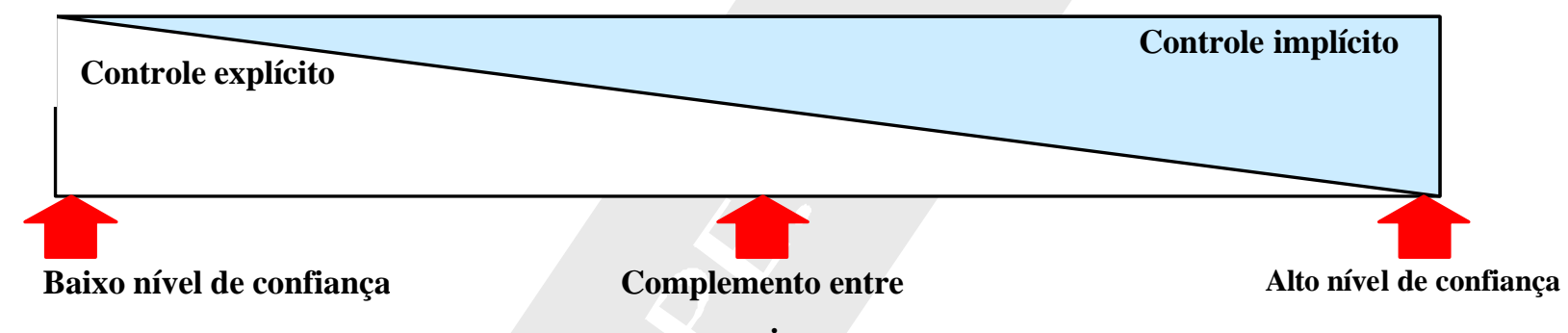

Fonte: baseado em modelo apresentado por Birgitta Wolff. Mimeografado.

\section{A nova economia informacional}

O processo pelo qual surge a nova economia informacional talvez encontre o seu melhor suporte teórico no clássico argumento schumpeteriano sobre o processo de "destruição criativa" do sistema capitalista. Schumpeter (1942) caracterizou o capitalismo moderno como uma constante "destruição criativa“", precondição para a competitividade. Schumpeter entendeu que a competição e a inovação são características intrínsecas ao capitalismo. Portanto, em maior ou menor grau, todas as empresas estão sujeitas a essa dinâmica que tem como motor a inovação, a informação e o conhecimento. Na nova economia informacional há um aumento exponencial dessa dinâmica.

Castells (1999, p.226), por sua vez, afirma que a nova economia informacional é em si mesma um processo de ruptura entre dois paradigmas da produção econômica:

- o tradicional processo "industrial" baseado em capital intensivo e na economia de escala e 
- o novo processo "informacional“, orientado pela contínua inovação das tecnologias de informação e comunicação, com base na informação e no conhecimento como principais meios de produção de riqueza.

A nova economia informacional é caracterizada por um conjunto de inovações institucionais. Trata-se de uma nova configuração macroeconômica que tem como meio e motor o avanço das tecnologias de informação e comunicação (TIC). Essas inovações institucionais afetam as economias nacionais e internacional pela abertura, em vários países, de mercados cativos (desregulamentação)ao investimento externo, pelo maior fluxo mundial de capitais, pela privatização de empresas estatais, pela expansão das empresas multinacionais, por uma alta competitividade a nível internacional e através da contínua inovação tecnológica. A conjunção desses fatores proporcionou novas oportunidades de mercado, o surgimento de nova tecnologias, novos produtores e serviços, além de novas formas organizacionais e de uma nova dinâmica nas relações de trabalho. Sua principal conseqüência é a configuração de um ambiente de negócios incerto e de grande risco, exigindo das empresas uma constante adaptação às mudanças.

Nesse sentido, podemos identificar três importantes fatores que geram incerteza e que estão interrelacionados no ambiente institucional:

- as incertezas geradas por causas políticas e legais relativas à desregulamentação de mercados, à privatização de empresas estatais e ao processo de regulamentação da competição entre as empresas, depois da privatização. Freqüentemente, devido ao processo regulatório, essas empresas operam sob regras de mercado indefinidas ou em processo de definição;

- as incertezas relacionadas ao contínuo processo de inovação tecnológica; e

- as incertezas referentes às condições de um mercado extremamente competitivo, com demandas incertas e irregulares, a exigir a gestão de soluções cada vez mais complexas num curto período de tempo.

Para Burton-Jones (1999), o que tem causado maior impacto na relação empresa/empregado é a predominância de contratos de trabalho mais transacionais, de curto prazo e de caráter menos implícito. O principal argumento é o de que do ponto de vista institucional o novo contexto tem redefinido as relações humanas, despertando menor confiança interpessoal dentro das empresas. Nessa nova realidade, são identificados três aspectos fundamentais, relacionados com os níveis de confiança interpessoal:

- $\quad$ atividades econômicas coordenadas através de redes de relacionamento;

- nova dinâmica do trabalho humano; e

- configuração de uma nova dinâmica de negócios:

\section{Coordenação em redes de relacionamento}

A atividade produtiva na nova economia informacional é especialmente caracterizada pela coordenação através de redes de relacionamentos entre empresas e/ou indivíduos. Essa coordenação através de redes é uma resposta à necessidade de constante adaptação das estruturas organizacionais e produtivas a ambientes de alta incerteza. As redes proporcionam uma grande flexibilidade dos meios de produção, além de disponibilidade de informação. A formação dessas redes de relacionamento é parte da própria gênese do processo de inovação na indústria da tecnologia de informação e comunicação, verificado nas últimas décadas.

Fukuyama (2000) fala da importância da formação de redes de relacionamentos no Vale do Silício (EUA) berço do desenvolvimento tecnológico e do surgimento de muitas das novas empresas que se tornaram expoentes da nova economia informacional - como uma forma de coordenação fundamental para o processo de inovação. Isso se deve ao fato da coordenação em redes estar intimamente relacionada ao modelo de transformação organizacional de burocracias verticais para corporações horizontais, devido à já mencionada necessidade de rápida adaptação às condições de imprevisibilidade num contexto de mudanças econômicas e tecnológicas (CASTELLS, 1999, p.184). 
Contudo, diferentes formas de coordenação de atividades econômicas através de redes intra-organizacionais e interorganizacionais surgiram com a nova economia informacional; seja entre empresas, unidades de produção e especialistas. Essa distinção é apontada por Castells (1999) quando se refere à formação de alianças estratégicas, redes de subcontratação centralizadas em grandes empresas, redes horizontais de pequenos e médios negócios, ou mesmo redes informais formadas por especialistas. Burton-Jones (1999, p.138) comenta sobre as diferentes relações de poder e controle, definindo distintas formações em redes. Farley e Kobrin (1995, p.214) analisam a vantagem das redes intra-organizacionais para se lidar com altos índices de incerteza. Entretanto, notase que apesar dos diferentes tipos de configuração em rede, estas possuem um mesmo sentido que é o de substituir as relações burocráticas e hierárquicas tradicionais por formas híbridas de coordenação, mais ágeis e eficientes.

Segundo Fukuyama (2000) a importância das redes informais - definidas como grupos sociais com normas e valores comuns - é que elas provêem canais alternativos para o fluxo de informações, não apenas para dentro das organizações como através delas. Além disso, pode-se entender que a flexibilidade de coordenação através das redes também está relacionada com a natureza modular dos componentes de produção na nova economia informacional (LEVY e SPILLER, 1994).

Cooper e Burke (2002, p.204) atribuem à internet um papel fundamental na distribuição e disponibilidade in stantânea da informação nos diversos níveis hierárquicos, conectando em rede parceiros, empregados, fornecedores, contratados externos e clientes. As redes proporcionam às empresas da indústria de tecnologia da informação e comunicação, maior facilidade de acesso, armazenamento, processamento e de distribuição da informação, dentro e fora da empresa. O que difere uma simples relação contratual de suprimento de materiais (ou outsourcing) da coordenação de atividades através de redes informais é que esta se desenvolverá sob relações menos formais, mais igualitárias, interdependentes e cooperativas. Essas relações informais vão além do que pode ser previamente acordado por contratos formais, pois a oferta de soluções tecnológicas, normalmente, envolve maior imprevisibilidade e grande necessidade de adaptação às contingências que não podem ser completamente previstas em contratos formais. Isso exige que muitas dessas relações sejam estabelecidas por contratos informais entre empresas e indivíduos, com base na reciprocidade e na confiança mútua.

As redes de relacionamento informais são essenciais para o desenvolvimento tecnológico por várias razões. Independente da existência ou não de contratos formais, indivíduos buscam estabelecer relações informais além das fronteiras de suas empresas. Isso ocorre porque o conhecimento específico, necessário para a oferta de soluções, frequientemente requer a presença de diferentes especialistas em diferentes empresas fornecedoras ou parceiras. Essas relações interpessoais garantem o constante aperfeiçoamento, o atendimento personalizado e a solução de problemas técnicos na prestação do serviço ao cliente. Grande parte do conhecimento é tácita e não pode ser facilmente reduzida a um bem de conveniência a ser comprado e vendido num mercado de propriedade intelectual (DON e RUECROFT, 1999). Além disso, as redes de relacionamento funcionam como uma garantia de empregabilidade diante das incertezas do mercado de trabalho.

No entanto, a coordenação em rede também acarreta problemas mais complexos para os modelos de gestão mais tradicionais. Como argumenta Argandona (2003, p.12.), de uma certa forma, a configuração das redes transfere o centro de autoridade e decisões e promove uma mudança geral nos custos, integrando e separando agentes. As unidades de decisão são transferidas para cada projeto, os quais normalmente se combinam com uma variedade de outras empresas e indivíduos, criando uma complexa rede de relacionamentos entre clientes, parceiros e fornecedores de projetos desenvolvidos através de diversas formas contratuais e organizacionais. Isso sugere maior necessidade de confiança para que essas transações sejam efetivadas. Argandona (2003) comenta que o contrato social entre stakeholders nessas empresas torna-se objeto de constante revisão e mudança, o que pode comprometer a confiança, despertando resistência à mudança, incerteza e desconforto. 


\section{Uma nova dinâmica do trabalho}

É o segundo aspecto fundamental da nova economia informacional relacionado com os níveis de confiança interpessoal. O fenômeno é bem caracterizado por Castells (1999) através de uma análise comparativa entre os paradigmas do industrialismo e do informacionalismo. Segundo o autor (ibidem, p.35):

o que é específico ao modo informacional de desenvolvimento é a ação de conhecimentos sobre os próprios conhecimentos como principal fonte de produtividade. O processamento da informação é focalizado na melhoria da tecnologia do processamento da informação como fonte de produtividade, em um círculo virtuoso de interação entre as fontes de conhecimentos tecnológicos e a aplicação da tecnologia para melhorar a geração de conhecimentos e o processamento da informação.

O informacionalismo visa ao desenvolvimento tecnológico; ou seja, à acumulação de conhecimentos e a maiores níveis de complexidade do processamento da informação. Embora um grau mais elevado de conhecimento geralmente resulte num melhor nível de produção por unidade de insumos (como no industrialismo), Castells (1999, p.35) considera que a busca por conhecimentos e informação caracteriza a produção tecnológica no informacionalismo. Assim, o conhecimento é gerado e aplicado no próprio processo de desenvolvimento tecnológico. É estabelecida, para seu contínuo aprimoramento, uma dinâmica de trabalho "em espiral" no uso do conhecimento; além do fato de que a informação é determinada pela sua volatilidade e por seu valor de troca.

Dantas (2002, p.142) comenta que o indivíduo inserido na produção da informação tem como tarefa receber, processar e transmitir um conjunto de informações necessárias ao trabalho de outros indivíduos ou do subsistema com o qual interage. Segundo o autor, o que distingue esses indivíduos é a capacidade e a competência técnica para buscar e processar um volume maior ou menor de dados, com maior ou menor grau de complexidade (ou de redundância), em cada atividade e num determinado tempo. Dantas (2002, p.142-144) afirma que o valor da informação é determinado pelo tempo de trabalho que possibilita economizar. A informação não pode ser estocada e é altamente perecível. Para Dantas, são armazenados apenas os suportes materiais contendo dados que se tornam informação quando postos em "relação comunicativa". Uma vez processada e comunicada, a informação perde o seu valor original. Seu valor não se realiza por meio da troca como uma mercadoria, mas através da interação, da comunicação. É essa dinâmica que caracteriza a eficiência dos sistemas de produção na era informacional.

Essa nova dinâmica apresenta dois problemas para a gestão de recursos humanos. Primeiro, o surgimento de questões relativas aos direitos de propriedade. Afinal, a quem pertence o conhecimento? Segundo Argandona (2003, p.13-14), esse problema pode ser solucionado com relativa facilidade quando o conhecimento é disponibilizado externamente, através, por exemplo, de informações num banco de dados. Contudo, o problema se torna muito complexo quando esse conhecimento (e também as habilidades, as atitudes e os valores) é retido por pessoas ou grupos. O segundo problema é a grande dificuldade para se mensurar a performance individual, uma vez que, nesse processo, não se pode definir claramente as contribuições e os resultados individuais.

O perfil do trabalho na nova economia informacional é caracterizado por tarefas multifuncionais e variáveis; freqüentemente envolvendo variados grupos de especialistas. Nesse sentido, torna-se um desafio gerencial mensurar as contribuições individuais num processo criativo baseado no conhecimento e nos relacionamentos entre agentes, como, por exemplo, no desenvolvimento de soluções tecnológicas ou na implementação de complexos processos de informação. O resultado é a possível ineficácia da aplicação das estruturas tradicionais de remuneração baseadas em resultados, o que pode gerar insatisfação e desmotivar os empregados. Argandona (2003) ainda caracteriza as condições de trabalho nas empresas da nova economia informacional como "mais precárias" e mais favoráveis ao surgimento de problemas relacionados à lealdade, justiça e transparência. São aspectos que sugerem a predominância de contratos informais para lidar com o problema através do alinhamento de interesses individuais e organizacionais, num contexto em que a confiança se torna um elemento ainda mais crítico. 


\section{Uma nova dinâmica de negócios}

Esse terceiro aspecto fundamental da nova economia informacional decorre da alta volatilidade da tecnologia e do mercado; e essa nova dinâmica se processa num ambiente altamente competitivo, incerto e de risco, em que o tempo é um recurso crítico.

Tecnologias são oferecidas ao mercado como "soluções" de informação e/ou comunicação, não sendo claramente caracterizadas como produtos ou serviços. Para terem sucesso em novos mercados, tais soluções requerem uma maior percepção do valor que lhes é atribuído pelo cliente, considerando-se a possibilidade de que atendam suas necessidades imediatas, ao reduzir custos e/ou melhorar a qualidade dos serviços, levando ao sucateamento imediato da tecnologia anterior. Esse processo esgota rapidamente as possibilidades de extensão do ciclo de vida das tecnologias e conseqüientemente reduz o ciclo de vida das soluções derivadas dessas tecnologias, o que gera uma demanda contínua por inovação.

Para essas empresas, o diferencial competitivo pode muitas vezes estar na capacidade técnica de desenvolvimento de novas soluções - a partir das tecnologias existentes ou simplesmente da substituição por tecnologias novas ou semelhantes - que ofereçam maior percepção de valor. Contudo, essa é uma perspectiva que se mantém por um espaço de tempo relativamente curto, pois é marcada pelo seguinte paradoxo: assim como a tecnologia se torna o meio principal - motor da nova economia -, também pode ser facilmente reproduzida e sucateada, deixando de ser um diferencial competitivo que assegure sustentabilidade econômica à empresa provedora.

Ao mesmo tempo em que a tecnologia pode reduzir significativamente custos do processo produtivo, ela não é um diferencial competitivo por muito tempo. Dessa forma, o desenvolvimento tecnológico é direcionado pela competição através da antecipação de futuras demandas, exigindo das empresas provedoras agilidade e flexibilidade nos processos produtivos. Além do mais, a presença de um ambiente altamente competitivo acelera e estimula constantemente as atividades comerciais e de marketing, que em muitos casos são fundamentais para a sobrevivência das empresas. Nesse aspecto, cabe observar que frequientemente as empresas da nova economia informacional desenvolvem instrumentos de marketing como meios fundamentais para a competição, principalmente em mercados de massa, como os de telefonia celular e internet. A vantagem competitiva nesses mercados vai estar muito relacionada com o capital humano, a habilidade gerencial de fomentar um processo intensivo e contínuo de inovação (baseado em conhecimento) e com uma apurada sensibilidade para o mercado competitivo. Isso requer habilidade para conciliar a gestão de distintos processos temporais - como o tempo de desenvolvimento de soluções e o tempo para a sua comercialização-, exigindo uma complexa coordenação de tarefas especializadas em redes internas e externas.

A crescente complexidade das soluções oferecidas exige não somente um tipo de conhecimento específico, mas um conjunto de conhecimentos sobre tecnologias convergentes. Assim, essas empresas são freqüentemente levadas a formar redes de parcerias e a se associarem com outras empresas fornecedoras e distribuidoras. A agilidade em sincronizar estrategicamente o desenvolvimento de soluções tecnológicas, formar e manter alianças e parcerias, bem como a habilidade de negociar com clientes e fornecedores em tempo hábil são fatores de sucesso que podem garantir a sobrevida dessas empresas.

Essa dinâmica comumente acontece num ambiente de grande incerteza sobre as demandas futuras e sobre a extensão potencial do ciclo de vida das soluções; e nesse contexto não são raros os casos de fracasso. O que se observa é a transferência das perspectivas transacionais de curto prazo da dinâmica de mercado para a organização interna das empresas. Como afirma Dantas (2002), muitas vezes essas empresas estão comprometidas com perspectivas de investimento e retorno de curto prazo, devido à natureza do capital de risco (venture capital), muito empregado no seu desenvolvimento desde os anos 1950. Ademais, adotam estratégias que seguem a mesma dinâmica.

Segundo Cyert e March (1963), cenários de maior incerteza sugerem a adoção de estratégias de curto prazo, o que gera dois grandes problemas: (1) o primeiro é que geralmente a evolução tecnológica é desproporcional à capacidade de adaptação das empresas. Torna-se constante a necessidade de reorganização, redimensionamento e reposicionamento dos recursos (interna e externamente) através, por exemplo, da formação de redes de parce- 
rias. O processo de decisão na escolha de uma determinada tecnologia causa impacto na escolha e contratação de fornecedores, na qualidade e quantidade dos recursos contratados, bem como nos investimentos para o desenvolvimento e lançamento de novos produtos. O resultado é uma gestão organizacional marcada por constantes reestruturações e lay-offs da mão-de-obra. Essas práticas estabelecem uma relação entre empregado e empregador menos codependente, com perspectivas de curtíssimo prazo, o que conseqüientemente afeta as relações internas baseadas na confiança, que podem ser construídas ao longo do tempo. (2) Simultaneamente, ocorre a perda da capacidade de monitoração e de implementação de regras formais e informais, devido à necessidade de constante reorganização. Aqui um paradoxo se estabelece, especialmente, levando em conta que na rotina de trabalho dessas empresas os indivíduos devem interagir o tempo todo, compartilhando seu conhecimento na forma de informação sensível, de idéias e de tarefas comuns, como parte do processo produtivo. Ainda que isso possa sugerir uma maior dependência de contratos informais baseados em relacionamento, nesse contexto, a confiança torna-se cada vez mais um elemento raro para a promoção da cooperação espontânea.

\section{As empresas da nova economia informacional}

A nova economia informacional não é considerada um fenômeno setorial, mas está relacionada a um fundamental "redesenho" de produtos e à reestruturação da produção tecnológica por toda a economia (KIEL INSTITUTE OF WORLD ECONOMICS, 2004). No entanto, as empresas que surgem estreitamente associadas e influenciadas por essa nova economia apresentam características singulares em sua forma de organização, no seu sistema de produção e no seu ambiente de trabalho.

Argandona (2003, p.4) descreve como essa nova economia tem afetado em diferentes graus a economia como um todo e com diferente intensidade cada indústria.

Estritamente falando, a nova economia expressa o impacto causado pela revolução tecnológica nas comunicações e na informação. Primeiro, nos setores vinculados à produção de bens de tecnologia da informação e comunicação e à prestação de serviços; depois, nas indústrias que empregam esses produtos como bens de produção. Em seguida, nas outras indústrias e na economia como um todo.

Castells (1999) também destaca essa relação entre as indústrias de tecnologia da informação e comunicação especialmente, a indústria das telecomunicações - e os demais setores industriais. Castells vê nas empresas produtoras de tecnologia da informação e telecomunicações a origem das mudanças organizacionais (p.97), considera que representam o segmento que mais sofreu os efeitos das mudanças institucionais (p.104) e que são a principal ferramenta de competitividade global (p.106).

Esse setor mais particularmente condicionado pelas mudanças responde pela produção, armazenamento e distribuição da informação e tem como atividade-fim a oferta de soluções. Algumas dessas empresas eram estatais que recentemente sofreram ampla reestruturação com a privatização ocorrida em diversos países. Outras surgiram com o estabelecimento de um novo modelo competitivo pela desregulamentação e a abertura de novos mercados. Existem ainda aquelas surgidas a partir do desenvolvimento de novas tecnologias que abriram novas oportunidades no mercado.

Castells (1999, p.184-185.) aponta sete tendências principais das empresas na nova economia informacional, durante a transição de burocracias verticais para corporações horizontais:

- são organizações estruturadas em torno de processos, não da tarefa;

- a hierarquia é horizontal;

- gerenciamento é em equipe;

- a medida do desempenho é determinada pela satisfação do cliente;

- a recompensa é dada com base no desempenho da equipe;

- maximização dos contatos com fornecedores e clientes; e 
- informação e treinamento constante de funcionários em todos os níveis.

Todas essas tendências estão relacionadas diretamente com a gênese da coordenação em rede, e na realidade muitas de suas operações são conduzidas por outras empresas (subcontratadas, auxiliares e parceiras), que ao mesmo tempo podem cooperar ou competir, de acordo com as oportunidades.

Entretanto, já que o mercado de trabalho na nova economia informacional é marcado pela incerteza e a insegurança, freqüentemente, há um forte pressão sobre os trabalhadores dessas empresas. Essa pressão se traduz na redução da oferta de emprego no período pós-privatização, pela reestruturação dos tradicionais monopólios estatais, pelos constantes lay-offs e pelo redimensionamento dos recursos humanos em consequiência das situações impostas pelo modelo competitivo.

Um estudo da Organização Internacional do Trabalho (OIT) intitulado World Employment Report 2001: Life at Work in the Information Economy mostra muitos dos efeitos da nova economia informacional. Apesar do tom otimista, o relatório considera o trabalho sob essa nova economia como um balanço de potenciais oportunidades em meio a grandes riscos e incertezas. O caso brasileiro é destacado, sob a denominação de "modernização dolorosa". O documento revela uma expressiva variação negativa da oferta de trabalho na indústria brasileira de tecnologia da informação e comunicação, a eliminação das tradicionais industrias tecnológicas nacionais imposta pela competitividade e uma grande dependência do investimento estrangeiro. Em outro relatório (2002), a OIT discute o emprego, a empregabilidade e a igualdade de oportunidades, focando a indústria das telecomunicações. Nesse documento, aponta uma redução generalizada da oferta de emprego e a precariedade dos postos de trabalho, com algumas diferenças entre os países. Segundo esse relatório, embora não seja uma tendência global, é possível constatar alguma expansão do emprego no setor, num determinado período, como nos casos da Alemanha, da Itália, dos EUA e do Japão na década de 1990. Esse fenômeno seria explicado pelo ingresso no mercado de empresas concorrentes e da expansão tanto da telefonia móvel quanto das chamadas empresas "pontocom".

No entanto, cabe observar que isso não se sustentou nos anos seguintes. De uma maneira geral, mesmo em alguns daqueles países, e principalmente depois de 2001, novas demissões ocorreram em todo o mundo devido à desaceleração da economia e aos movimentos de reestruturação através de fusões, aquisições e formação de joint-ventures. Ainda segundo a OIT (2002), o problema está na qualidade das vagas que se abrem, verificandose além disso uma tendência à maior precariedade das condições do trabalho em segmentos do já referido setor de telecomunicações, citando como exemplos a Espanha, a Itália, o Japão e a Argentina (GARCIA, 2005). Segundo Garcia (2005), o processo em curso nas empresas desse segmento, freqüentemente, impõe prejuízos aos empregados. Burton-Jones (1999) mostra que nessas empresas vem proliferando o emprego temporário, de meia jornada e o trabalho autônomo.

Devido a esse cenário de constante adaptação às mudanças e reorganizações, as empresas da nova economia informacional geralmente apresentam índices bem maiores de rotatividade de empregados, quando comparadas com as indústrias mais tradicionais. Ainda de acordo com Burton-Jones (1999, p.53), no final dos anos 1980 e durante a década de 1990, empresas como IBM e AT\&T abandonaram a política de não-demissão, colocando seus contratos sob pressão implícita, o que aumentou a insegurança entre os "sobreviventes" das reestruturações. Nesse sentido, o autor comenta que tais medidas têm contribuído para gerar falta de confiança nas relações entre empresa e empregado, movendo o antigo modelo de contrato relacional na direção de um modelo de contrato transacional.

Dentre as muitas conseqüências das mudanças no mercado de trabalho, os cortes de pessoal podem ser a causa de sentimentos de incerteza, raiva, culpa e de falta de confiança entre aqueles que conseguem manter seus empregos (CAMPBELL, WORRALL e COOPER, 2000). Cabe observar que a tarefa de gerir maiores índices de rotatividade de empregados acaba dificultando o desenvolvimento de uma cultura corporativa mais adequada para lidar com um cenário de constantes mudanças.

Tosi, Rizzo e Carroll (1994) definem esse modelo de organização como “orgânico", referindo-se às empresas que operam sob alta volatilidade tecnológica e de mercado. Tal modelo é caracterizado por empresas mais fle- 
xíveis e descentralizadas, num ambiente sob forte transformação e que tende à ocorrência de maiores conflitos entre as pessoas. Essas empresas são definias pelos autores como job-shop-oriented, onde empregos são disponibilizados de acordo com a reorganização da produção. As empresas orgânicas quase não têm meios formais de monitoração, dependem muito das habilidades individuais e a mensuração da performance individual é baseada mais em dados "subjetivos" do que em medidas “objetivas". Ainda conforme Tosi, Rizzo e Carroll, nessas empresas, a mensuração da performance é baseada em estimativas futuras potenciais, não em dados históricos.

\section{Problemas propostos a serem analisados}

Aparentemente, surge um paradoxo para a gestão do capital humano nas empresas da nova economia informacional. Ao mesmo tempo em que é maior a necessidade de confiança interpessoal nas empresas, diante da contínua necessidade de adaptação às mudanças, mais difícil é estabelecer tal confiança nesse sistema social.

Essas empresas são conectadas em redes que comportam tarefas mais complexas e especializadas, baseadas na informação e no conhecimento intensivo, nas quais os mecanismos tradicionais de controle, monitoramento e mensuração de performance podem falhar. Essas organizações operam num ambiente de maior incerteza, risco e competição que leva à constante necessidade de reorganização e redimensionamento de seus recursos, sugerindo, portanto, estruturas mais descentralizadas, flexíveis e autogerenciadas. Outra característica a ser destacada é o fator crítico "tempo" para gerir um processo de inovação contínuo e um reduzido ciclo de vida dos produtos e serviços. Soma-se a isso a expectativa de aumento da demanda ou demandas irregulares. Quanto ao perfil do trabalho, pode ser definido como multifuncional, marcado por rotinas variáveis.

Esse conjunto de características sugere uma maior necessidade de contratos implícitos, como forma de enfrentar um alto grau de incerteza, e de relacionamentos calcados na confiança como mecanismo de controle e motivação para estabelecer a cooperação espontânea. Contudo, a análise aqui desenvolvida sugere que nas empresas da nova economia informacional são menores os níveis de confiança. Geralmente, são empresas cujo quadro de funcionários é mais jovem ${ }^{1}$ e sujeito à alta rotatividade, devido ao seu constante redimensionamento, seja por realocações ou lay-offs.

A performance individual é mensurada com base em dados mais subjetivos e marcada por ambigüidades. Isso ocorre em empresas recém-estabelecidas, ou em processo de reorganização, nas quais não é possível desenvolver uma cultura efetivamente corporativa ou mais adequada para lidar com os desafios das constantes mudanças. Nota-se que a competição agressiva do mercado é transferida para dentro das empresas, resultando numa maior monitoração horizontal, em meio a um ritmo de trabalho de longas jornadas diárias, em detrimento do lazer individual. Essa situação rompe com o sentido de comunidade na empresa (ARGANDONA, 2003, p.13-15) e induz a uma menor confiança entre os indivíduos.

Portanto, a principal hipótese aqui levantada é a de que as empresas da nova economia informacional apresentam níveis inferiores de confiança interpessoal, quando comparadas às empresas da economia tradicional, ou "velha economia". Apesar dos possíveis ganhos em termos de flexibilidade, do empreendedorismo e do maior poder individual, no geral, as condições de trabalho nas empresas dessa nova economia tendem a apresentar maiores obstáculos à motivação, ao comprometimento dos empregados e à percepção de justiça. Nesse contexto, as pressões por resultados de curto prazo acabam levando a um maior nível de stress, tornando mais difícil ainda estabelecer relações de cooperação calcadas na confiança.

Para melhor avaliar esse cenário, é preciso ainda analisar a confiança como uma variável independente, levando em conta sua relação com outros elementos da gestão e do comportamento organizacional. Dessa perspectiva, uma segunda questão é a provável relação entre os níveis de confiança e as taxas de rotatividade de empregados (turnover). A análise aqui formulada sugere a existência de uma relação negativa entre esse turnover e os níveis de confiança.

${ }^{1}$ Sutter e Kocher (2003) demonstram a tendência de aumento da confiança entre pessoas mais adultas. 
Deve ser observado ainda que as empresas da nova economia informacional não terão necessariamente uma performance inferior por causa de um possível menor nível de confiança. Níveis de confiança nas empresas são bens intangíveis desejáveis, mas que representam apenas uma das variáveis do capital social que podem contribuir para se avaliar a performance final da empresa. Nesse sentido, é importante entender melhor a relação entre os níveis de confiança e a performance empresarial, um dado que se for levado em conta pode ajudar a melhor compreender a eficiência relativa desse mecanismo implícito.

De mais a mais, outros elementos ligados ao comportamento organizacional podem ser analisados em relação aos níveis de confiança, como a insegurança no trabalho, o clima organizacional, a satisfação e o comprometimento dos empregados. Por exemplo, segundo Milgrom e Roberts (1992, p.30), o comprometimento dos empregados é fruto de elementos motivacionais. Uma vez entendido que confiança é uma condição necessária, mas não suficiente para se gerar níveis de comprometimento dos empregados, tais níveis de comprometimento devem estar relacionados a outros incentivos como bonificações e recompensas. Mesmo assim, a confiança interpessoal é um elemento de motivação intrínseca que pode ter uma relação positiva com o comprometimento.

Whitener (1998) apresenta um estudo sobre alguns elementos diretamente relacionados com a confiança, tais como a qualidade da comunicação interna, a percepção de integridade, a consistência e a preocupação com os empregados, além da delegação e do compartilhamento da autoridade. Esse conjunto de variáveis também oferece uma melhor avaliação desses ambientes e da gestão dos bens intangíveis.

Por fim, cabe lembrar que estudos empíricos e interdisciplinares devem ser desenvolvidos para uma melhor compreensão tanto do fenômeno social dentro das empresas quanto da gestão de bens intangíveis, como é o caso dos níveis de confiança. Uma das lições aprendidas pelas empresas nas ultimas décadas é a de que a expectativa de ganhos pela melhoria na produtividade e pelos investimentos em novas tecnologias deve igualmente considerar futuros investimentos em recursos humanos e na reorganização da empresa. Isso significa que a performance depende não somente de habilidade na criação de bens tangíveis e intangíveis, mas também da capacidade de adaptação às condições de mudanças ambientais através da contínua renovação, reconfiguração e reposicionamento desses bens. 


\section{Referências bibliográficas}

ALCHIAN, A. A. How should prices be set? II Politico, V.32, N.02, p.369-382, 1967.

ARGANDONA, A. The new economy: ethical issues. Journal of Business Ethics, No.44, p.3-22, 2003.

ARROW, K .J. The limits of organization. New York: W. W. Norton \& Company Inc., 1974.

AXELROD, R. The evolution of cooperation. New York: Basic Books, 1984.

BRADACH, J. L.; ECCLES, R. G. Price, authority and trust: from ideal types to plural forms. Annual Review of Sociology, Vol.15, p.97-118, 1989.

BECKERT, J.; METZNER, A.; ROEHL, H. Vertrauenserosion als organisatorische Gefahr und wie ihr zu begegnen ist. In: Organisationsentwicklung, No.3, p.56-66, 1998.

BURTON-JONES, A. Knowledge capitalism - business work and learning in the new economy. London, UK: Oxford University Press, 1999.

BUTTER, F. A. G. den; MOSCH, R. H. J. Trade, trust and transaction costs. Department of Economics, Vrije Universiteit Amsterdam; Tinbergen Institute. Disponível em: <http://papers.ssrn.com/sol3/papers.cfm?abstract_id=459501>. Acesso em: 10 fev. 2005. (Discussion paper, version 7, Oct. 2003).

CAMPBELL, F.; WORRALL, L; COOPER, C. The psychological effects of downsizing and privatization. University of Wolverhampton, UK, 2000. (Working Series, No. WP001/00)

CASTELLS, M. A sociedade em rede. 4. ed. São Paulo: Paz e Terra, 1999.

CHILES, T. H.; M CMACKIN, J.F. Integrating variable risk preference, trust and transaction cost economics. Academy of Management Review, Vol.21, No.01, p.72-99, 1996.

COLEM AN, J. Foundations of social theory. Cambridge, MA and London: Harvard University Press, 1990.

COOPER, C. L.; BURKE, R. J. The new world of work - challenges and opportunities. Oxford, UK: Blackwell, 2002.

CORIAT, B.; GUENNIF, S. Self-interest, trust and institutions. In: LAZARIC, N.; LORENZ, E. (Ed.). Trust and economic learning. Cheltenham, UK: Edward Elgar, 1998.

COUTU, D. Trust in virtual teams. Harvard Business Review, Boston, p.20-1, May/J une 1998.

COWAN, R.; JONARD, N.; ZIMMERMANN, J. Strategic alliances, innovation and emergence of organized proximity. Disponível em: <www.druid.dk/conferences/summer2004/papers/ds2004-59pdf>. Acesso em: 10 fev. 2005. (Working paper, Elsinore, Denmark, June 1416, 2004.).

CYERT, R. M.; MARCH, J.G. A behavioral theory of the firm. Englewood Cliffs, NJ: Prentice- Hall, 1963.

DANTAS, M. A lógica do capital-informação. 2. ed. Rio de Janeiro: Contraponto, 2002.

DEUTSCH, M. Trust and suspicion. The Journal of Conflict Resolution, Vol.2, N.04, p.265-279, 1958.

Cooperation and trust: some theoretical notes. In: J ONES, M. R. (Ed.). Nebraska Symposium on Motivation. Lincoln: University of Nebraska Press, 1962. p.275-319.

DIRKS, K. T.; FERRIN, D. L. The role of trust in organizational settings. Organization Science, Vol.12, N.04, p.450-467, 2001.

DON, E. K.; RUECROFT, R. W. The complexity challenge: technological innovation for the 21st century. Londres: Pinter, 1999.

DUNN, J. Trust and political agency. In: GAMBETTA, D. (Ed.). Trust: making and breaking cooperative relations. Disponível em: $<$ <ttp://www.sociology.ox.ac.uk/papers/dunn73-93.doc>. Acesso em: 15 jan. 2005. (Electronic edition. Department of Sociology, University of Oxford, chapter 5, p.73-93,2000).

FARLEY, J.; KOBRIN, S. Organizing the global multinational form. In: BOWMAN, E.H.; KOGUT, B.M. (Ed.). Redesigning the firm. New York: Oxford University Press, 1995. p.197-217.

FUKUYAMA, F. Confiança - as virtudes sociais e a criação da prosperidade. Rio de Janeiro: Rocco, 1996.

A grande ruptura - a natureza humana e a reconstrução da ordem social. Rio de Janeiro: Rocco, 2000.

GAM BETTA, D. Can we trust trust? In: GAM BETTA, D. (Ed.). Trust: making and breaking cooperative relations, New York: Blackwell, 1988.

GARCIA, S. R. Privatização e emprego no setor de telecomunicações: novas oportunidades ou degradação do trabalho? 0 caso do Rio Grande do Sul. Disponível em: <http://www.ub.es/geocrit/sn/sn-170-12.htm>. Acesso em: 10 fev. 2005.

GILLESPIE, N. Measuring trust in working relationships: the behavioral trust inventory. work submitted to the Journal of Applied Psychology. University of Melbourne, M elbourne, Australia, June 2003. 
GIBBONS, R. Trust in social structures: Hobbes and Coase meet repeated games. In: COOK, K. (Ed.). Trust in society. New York: Russell Sage Foundation, 2000.

HAYEK, F. Spontaneous ('grown') order and organized ('made') order. In: THOM PSON, G. et al. (Ed.). Markets, hierarchies \& networks the coordination of social life. London: Sage, 1998. p.293-301.

JARVENPAA, S. L., KNOLL, K.; LEIDNER, D. E. Is anybody out there? Antecedents of trust in global virtual teams. Journal of Management Information Systems, v.14, n.4, p.29-64,1998.

KIEL INSTITUTE FOR WORLD ECONOM ICS. Disponível em: http://www.uni-kiel.de/ifw/projects/neweco.htm>. Acesso em: 10 dez. 2004.

KLEIN, B.; CRAWFORD, R. G.; ALCHIAN, A. A. Vertical integration, approbrible rents, and the competitive contracting process. Journal of Law and Economics, v.XXI, n.2, p.297-326, Oct. 1978.

KREPS, D. M. Corporate culture and economic theory. In: ALT, J.; SHEPSLE, K. (Ed.)., Perspectives on Positive Political Economy, Cambridge: Cambridge University Press, p.90-143,1990.

LANE, C.; BACHMANN, R. Trust within and between organizations - conceptual issues and empirical applications. London, UK: Oxford University Press, 1998.

LANGFRED, C. W. Too much of a good thing? Negative effects of high trust and individual autonomy in self-managing teams. Academy of Management Journal, v.47, n.3, p.385-399, June 2004.

LEVY, B.; SPILLER, P. T. The institutional foundations of regulatory commitment: a competitive analysis of telecommunications regulation. Journal of Law, Economics and Organization, v.10, n.2, p.201-246, Fall 1994.

LORENZ, E. H. Neither friends nor strangers: informal networks of subcontracting in French industry. In: GAM BETTA, D. (Ed.). Trust: making and breaking cooperative relations. Disponível em :<http://www.sociology.ox.ac.uk/papers/lorenz194-210.doc>. Acesso em: 15 jan.2005. (Electronic edition. Department of Sociology, University of Oxford, chapter 6, p. 194-210, 2000.).

LUHMANN, N. Familiarity, confidence, trust: problems and alternatives. In: GAMBETTA, D. (Ed.). Trust: making and breaking cooperative relations. Disponível em: <http://www.sociology.ox.ac.uk/papers/luhmann94-107.doc>. Acesso em: 15 jan.2005. (Electronic edition. Department of Sociology, University of Oxford, chapter 6, p. 94-107, 2000.).

MILGROM, P.; ROBERTS, J. Economics, organization and management. New Jersey, NJ : Prentice Hall, 1992.

NOOTEBOOM, B. Trust, opportunism and governance: a process of control model. Organization Studies, v.17, n.6, p.985- $1010,1996$.

OIT. Reunión tripartita sobre empleo, empleabilidad e igualdad de oportunidades en los servicios de correos y telecomunicaciones, Genebra, 2002.

OSTROM , E. Governing commons: the evolution of institutions for collective action. Cambridge: Cambridge University Press, 1990. $\overline{2} \overline{2}, \overline{1} 9 \overline{9}$.

A behavioral approach to the rational choice theory of collective action. American Political Science Review, Vol.92, No.01, p.1-

OUCHI, W. G. Markets bureaucracies and clans. Administrative Science Quarterly, Vol.25,No.01, p.129-141, 1980.

PUTNAM, R. D. Comunidade e democracia - a experiência da Itália moderna, Rio de Janeiro: FGV Editora, 1996.

RIPPERGER, T. Ökonomik des Vertauens. Tübingen: Mohr Siebeck, 1998.

RING, P. S.; VAN DE VEN, A. H. Structuring cooperative relationships between organizations. Strategic Management Journal, Vol.13, p.483-98, 1992

ROLLAND, N.; CHAUVEL, D. Knowledge transfer in strategic alliances. In: DESPRES, C.; CHAUVEL, D. (Ed.). Knowledge horizons: the present and the promise of knowledge management. Boston, MA: Butterworth Heinemann, 2000. p.225-236.

ROBERTS, J. From know-how to show-how? Questioning the role of information and communication technologies in knowledge transfer. Technology Analysis and Strategic Management, v.12, n.4, p.429-443, 2000.

; VAN DEN STEEN, E. Human capital and corporate governance. In: SCHWALLBACH, J. (Ed.). Corporate governance essays in ho nor of Horst Albach. [S.I.]: Springer, 2001. p.128-143.

SEN, A. Isolation, assurance, and the social rate of discount. Quarterly Journal of Economics, v.81, n.1, 1967, p.112-124.

SCHUM PETER, J. A. Capitalism, socialism and democracy. New York, N.Y: Harper and Row Publishers, 1942. Republished by Harper $\&$ Colophon,1975.

SELZNICK, P. Leadership in administration - a sociological interpretation. New York: Harper\&Row, 1957.

SUTTER, M.; KOCHER, M. G. Age and the development of trust and reciprocity. Max Planck Institute for Research into Economic Systems - Jena, Germany; University of Innsbruck, Austria, 15 Dec. 2003. 
THOM PSON, G. Networks - introduction. In: THOMPSON, G.; FRANCES, J.; LEVACIC, R. E; M ITCHELL, J. (Ed.). Markets, hierarchies \& networks - the coordination of social Life. London: Sage, 1998. p.171-172.

TOSI, H. L.; RIZZO, J. R.; CARROLL, S. J. Managing organizational behaviour. 3. ed. Cambridge, MA: Blackwell Publishers, 1994.

VOGT, J. Vertrauen und Kontrolle in Transaktionen: eine institutionenökonomische Analyse, Wiesbaden: Gabler, 1997.

WEBER, M. Ensaios de sociologia. 5.ed. Rio de Janeiro: LTC, 2002.

WHITENER, E. M., BRODT, S., KORSGAARD, A. and WERNER, J., Managers as initiators of trust: an exchange relationship framework for understanding managerial trustworthy behavior. Academy of Management Review, Vol.23, p.513-530, 1998.

WILLIAMSON, O. Calculativeness, trust, and economic organization. Journal of Law \& Economics, Vol.36, N.01, (April), p.453-486, 1993.

WOLFF, B. Constitutional contracting and corporate constitution. In: PICOT, A.; SCHLCHT, E. (Ed.). Perspectives on contract theory.[S.I.]:Springer, 1996. p.95-108.

WORLD EM PLOYM ENT REPORT 2001: life at work in the information economy. International Labour Office, Geneva.

ZAND, D. E. Trust and managerial problem solving. Administrative Science Quarterly, Vol.17, p.229-239, 1972.

ZUCKER, L. G. Production of trust: institutional sources of economic structure, 1840-1920. Research in Organizational Behavior, Vol.8, p.53-111, 1986 